\title{
Characteristics of the Temporal Variation in Temperature and Precipitation in China's Lower Yellow River Region
}

\author{
Heli Lu, ${ }^{1,2,3}$ Wenlong Jing, ${ }^{3}$ Jincai Zhao, ${ }^{3}$ Xiaojing Liu, ${ }^{3}$ and Zhong Huang ${ }^{3}$ \\ ${ }^{1}$ Institute of Natural Resources and Environmental Science, Henan University, Kaifeng 475004, China \\ ${ }^{2}$ Henan Collaborative Innovation Center for Coordinated Developments in Central China Economic Zone, Zhengzhou 450046, China \\ ${ }^{3}$ College of Environment and Planning, Henan University, Kaifeng 475004, China
}

Correspondence should be addressed to Heli Lu; cluheli@gmail.com

Received 17 June 2013; Accepted 27 November 2013; Published 23 February 2014

Academic Editor: Ismail Gultepe

Copyright (C) 2014 Heli Lu et al. This is an open access article distributed under the Creative Commons Attribution License, which permits unrestricted use, distribution, and reproduction in any medium, provided the original work is properly cited.

\begin{abstract}
We analyzed the spatial and temporal distributions of temperature and precipitation in China's Yellow River Region between 1960 and 2001 by compiling meteorological data using anomalies, climate trend rate, linear regression, trend analysis, spline functions, and other methods. The results show that the average temperatures in the Region have an upward trend at a rate of $0.19^{\circ} \mathrm{C}$ every 10 years. There are no significant changes in the Region's summers, but the winters have become visibly warmer, with the temperatures significantly increasing from the 1980s. The average annual precipitation rate has shown a downwards trend at a rate of $-11.7 \mathrm{~mm}$ every 10 years. Even though the precipitation rate shows variations, the amount of precipitation is inconsistent with the most significant decrease in precipitation rates being seen during summer followed by autumn, while the rates actually slightly increased during spring and winter. Over the 42 years, the Region as a whole showed a trend of climate warming and drying with $77 \%$ of the total sites studied showing these combined trends. Before the 1980s, mainly a drying and cooling trend was observed. In the mid-to-late 80 s the temperatures rose, resulting in the change to a warming and drying trend.
\end{abstract}

\section{Introduction}

According to the IPCC's fourth assessment report, temperatures across the globe have shown significant changes, with the most important being global warming [1]. Over the past century, the average global surface temperature has risen by $0.74^{\circ} \mathrm{C}$, with the magnitude of warming accelerating significantly since the 1990s [2-5]. China has seen the most significant occurrence of global warming with a temperature increase of $0.4-0.5^{\circ} \mathrm{C}$ over the past century. Since 1951, China has witnessed significant trends of temperature increase, especially in the winter, together with a decrease in precipitation rates.

The Yellow River Basin is located in the Northern Central area of China and mostly has a continental climate. The river itself has witnessed interannual variations in runoff and continuous periods of low water flow and the natural conditions of the Yellow River Basin tend to vary $[6,7]$.
These basic characteristics determine the sensitivity and vulnerability of the Basin's water resource system to climate change.

The Lower Yellow River Region is located within the East Asian Monsoons' area of influence and received the majority of its precipitation in the summer with large interannual variations in precipitation. The unique characteristics of concentrated annual precipitation and nonuniform spatial distribution exert pressure over water sources for local economic growth, which has been especially true since the 1970s $[8,9]$. A combination of natural and man-made elements causes frequent drying of the Lower Yellow River. This drying happened in 21 of the years between 1972 and 1998 and practically every year since the 90s [9]. These river dryings caused huge damage to both the local economy and ecosystem. This study chose temperature and precipitation data from 1960 to 2001 from 31 ground-based meteorological stations to conduct an in-depth investigation. To ensure the 


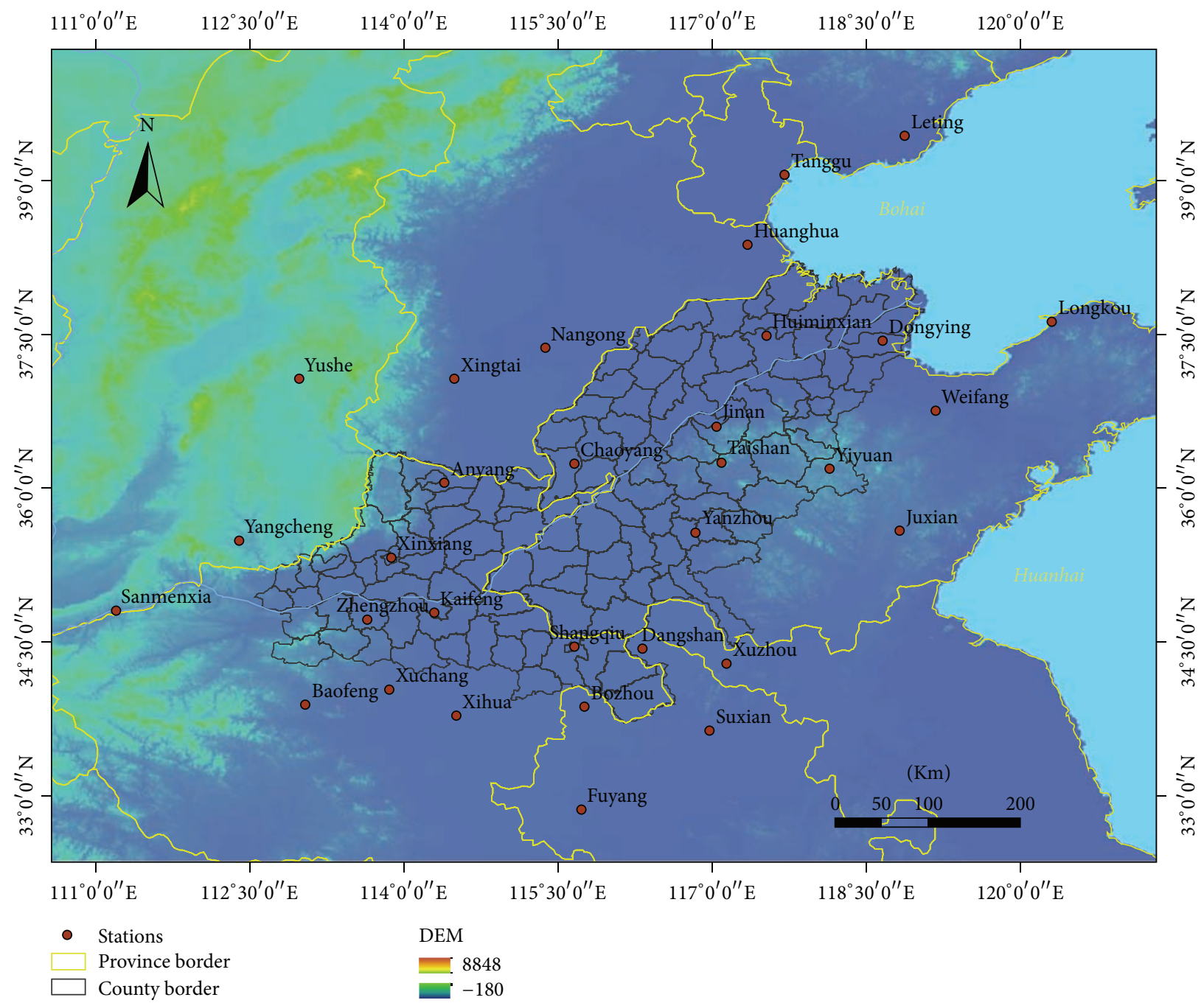

FIgURE 1: The Lower Yellow River Region and distribution of meteorological stations.

integrity of the meteorological data, we selected 11 stations within the Region as well as 20 outside the Region.

\section{Region of Study}

The Lower Yellow River is the section of the Yellow River south of the Taohua Valley located in the city of Zhengzhou in Henan province. The river is $785.6 \mathrm{~km}$ long and flows through the Henan and Shandong provinces with a drainage area of $22,000 \mathrm{~km}^{2}$. Owing to the large sediment content in the Yellow River, long-term deposition in the lower river has formed the world-famous "hanging river." This area is located east of the Bohai Sea, west of the inner continent, and has distinct land-sea thermal patterns, with a warm and mildly wet monsoon climate. The winter climate is cold and dry with prevailing northwest winds owing to the influence of the high-pressure system from the inner continent (Mongolia and Siberia). The summer climate is hot and humid with large amounts of precipitation resulting from the influence of warm air masses from the Pacific Ocean. The spring climate is dry with frequent sandstorms, while the autumns have clear skies and long days. These different climates show the significant changes that monsoon climates undergo throughout the year.

The annual precipitation rate in the Basin is around $700 \mathrm{~mm}$, which is very unevenly distributed and concentrated during the summer months. On the other hand, the interannual variation in precipitation rates is quite large; the Huabei Plains in the Lower Yellow River area are one of the areas with the largest interannual variation in precipitation rates in China. Precipitation rates can vary as much as 4-6 times between many different locations in the Region, but the variability in most locations is around $30 \%$. This area experiences both frequent droughts and floods resulting from the large variation in precipitation rates and high numbers of heavy thunderstorms.

The Lower Yellow River Region also faces large temperature variations throughout the year. It has hot summers and cold winters with clear differences between the four seasons and a large annual temperature range. The average annual 


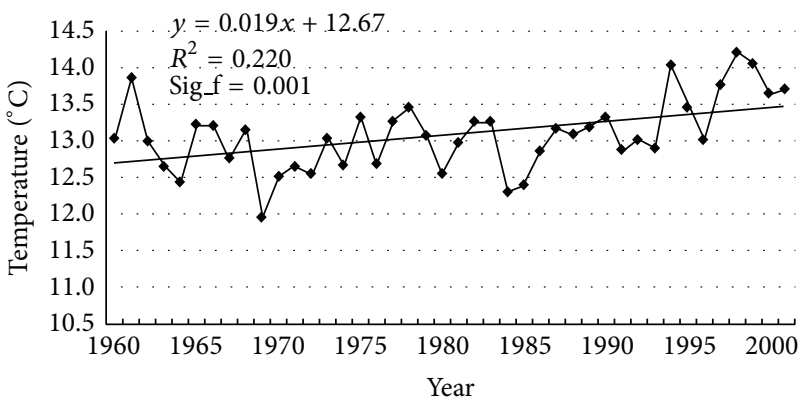

Figure 2: Average annual temperature trends in the Lower Yellow River Region from 1960 to 2001.

temperature is $6-15^{\circ} \mathrm{C}$ with the temperature being around $0^{\circ} \mathrm{C}$ in the coldest months and above $20^{\circ} \mathrm{C}$ in the hottest months. The weather has significant noncyclical changes. When cold outbreaks happen during the winter, the temperature can drop from 10 to $20^{\circ} \mathrm{C}$ within $14 \mathrm{~h}$. The annual period of sunshine is very long with a high average annual sunshine rate and large total amount of radiation from the sun. This abundant light resource provides excellent conditions for the growth of crops and use of solar energy.

\section{Method}

The meteorological data used for climate change analysis in this study were obtained from 31 ground-based meteorological stations (Figure 1), of which 11 were within the study area. To ensure the completeness of the meteorological data, 20 meteorological stations from outside the area of study were also used. The time frame being studied is that between the years of 1960 and 2001. The average area of each site sequence represents the Region's climate sequence. The temperature, precipitation rate, and anomalies for each station are calculated separately. January is most commonly designated as the coldest month and July as the warmest with March, April, and May being spring; June, July, and August being summer; September, October, and November being autumn; and December, January, and February being winter. These divisions are quite standard for temperate regions with clear seasonal differences. This study uses this division method to calculate the temperature, average precipitation rate, and anomalies of each season. It uses linear trend analysis to analyze climate change trends. Linear trend analysis and Mann Kendall trend can be produced for any time-series data. They are parametric procedures for trend testing and nonparametric alternatives to these procedures, respectively. To use one procedure or not should be evaluated in actual data in consideration of two aspects: power and efficiency. If residuals are normally distributed, the most powerful and the relative efficient test is the parametric procedure. As such linear trend analysis was preferred in our study. Actually Mann Kendall trend was also calculated and almost the same results were found. Furthermore spline interpolation is used to find the spatial interpolation for each station. This analysis shows the spatial distribution diagram for the temperature and precipitation trends in the area of study and calculates the spatial distribution of the interannual variation in temperature and precipitation. It also confirms the upward trend in temperatures across the Region for the period of time covered in the study.

\section{Data and Analysis}

\subsection{Temperature Change}

4.1.1. Interannual Temperature Change. The Lower Yellow River Region has shown a warming trend from 1960 to 2001, with the area of study showing an increasing trend for average annual temperatures at a rate of $0.19^{\circ} \mathrm{C}$ every 10 years $(\alpha<$ 0.01) (Figure 2).

From the average annual temperature data, we can see that the average annual temperature was lowest in the 1970s at $12.967^{\circ} \mathrm{C}$. There is no clear difference in annual temperature from the 1960 s to the 1970 s, but the temperature did increase from $0.031^{\circ} \mathrm{C}$ to $12.998^{\circ} \mathrm{C}$ from the 1970 s to the $1980 \mathrm{~s}$. The average annual temperature showed a clear increase from $0.545^{\circ} \mathrm{C}$ to $13.543^{\circ} \mathrm{C}$ from the 1980 s to the 1990 s.

4.1.2. Interannual Temperature Change Trends. From 1960 to 2001 the temperatures recorded at all the stations in the Lower Yellow River Region except Xuchang that displayed increasing average annual temperatures (Table 1), but there were some regional differences in these interannual trends (Figure 3). The temperature in Xuchang decreased at a rate of $-0.09^{\circ} \mathrm{C}$ every 10 years, which is insignificant, while the other study area stations' temperatures increased by $0.03-0.46^{\circ} \mathrm{C}$ every 10 years, with the most significant increases at Tanggu, Longkou, and Xingtai at a rate of $0.34-0.46^{\circ} \mathrm{C}$ every 10 years. The temperature at the stations of Chaoyang, Baofeng, Yushe, Weifang, Yanzhou, and Sanmenxia increased at a rate of less than 0.1, which is negligible. Looking at the entire Region, there is the partial characteristic of the average annual temperature distributions that are greater in the north-eastern part of the Region than the south-western and the temperature showed decreasing trends from north to south from 1960 to 2001. Looking at the entire time period, several clear trends emerge. From 1960 to 1970, the average temperature decreased at a rate of $-0.8^{\circ} \mathrm{C}$ with Tanggu, Laoting, Huanghua, and Huimin having the sharpest decreases at rates of $1.06 \sim 1.40^{\circ} \mathrm{C}$. Temperatures 
TABLE 1: Annual temperature trend, temperature trend in spring, temperature trend in summer, temperature trend in autumn, temperature trend in winter, and their significances.

\begin{tabular}{|c|c|c|c|c|c|}
\hline Station & Annual trend & Trend in spring & Trend in summer & Trend in autumn & Trend in winter \\
\hline Yushe & 0.06 & 0.09 & -0.07 & -0.01 & 0.23 \\
\hline Xingtai & $0.46^{* *}$ & $0.38^{* *}$ & $0.23^{* *}$ & $0.48^{* *}$ & $0.77^{* *}$ \\
\hline Anyang & $0.29^{* *}$ & $0.27^{*}$ & 0.12 & $0.32^{* *}$ & $0.46^{* *}$ \\
\hline Yangcheng & $0.13^{*}$ & 0.16 & -0.09 & 0.13 & $0.33^{* *}$ \\
\hline Xinxiang & $0.14^{*}$ & 0.20 & -0.08 & 0.14 & $0.30^{*}$ \\
\hline Leting & $0.33^{* *}$ & $0.37^{* *}$ & 0.15 & $0.24^{* *}$ & $0.55^{* *}$ \\
\hline Tanggu & $0.34^{* *}$ & $0.45^{* *}$ & $0.24^{* *}$ & $0.21^{*}$ & $0.45^{* *}$ \\
\hline Huanghua & $0.33^{* *}$ & $0.30^{* *}$ & 0.19 & $0.22^{*}$ & $0.48^{* *}$ \\
\hline Nangong & $0.17^{* *}$ & 0.14 & 0.00 & 0.13 & $0.43^{* *}$ \\
\hline Huiminxian & $0.24^{* *}$ & 0.20 & 0.10 & 0.18 & $0.49^{* *}$ \\
\hline Dongying & $0.30^{* *}$ & $0.37^{* *}$ & $0.19^{*}$ & 0.16 & $0.50^{* *}$ \\
\hline Longkou & $0.44^{* *}$ & $0.56^{* *}$ & $0.29^{* *}$ & $0.37^{* *}$ & $0.54^{* *}$ \\
\hline Chaoyang & 0.03 & -0.05 & -0.14 & 0.00 & $0.29^{*}$ \\
\hline Jinan & $0.24^{* *}$ & 0.23 & 0.06 & $0.20^{*}$ & $0.47^{* *}$ \\
\hline Taishan & $0.22^{* *}$ & 0.16 & 0.04 & $0.26^{*}$ & $0.41^{* *}$ \\
\hline Yiyuan & $0.23^{* *}$ & $0.26^{* *}$ & 0.07 & 0.13 & $0.46^{* *}$ \\
\hline Weifang & 0.07 & 0.04 & 0.07 & 0.01 & 0.17 \\
\hline Yanzhou & 0.09 & 0.03 & -0.07 & 0.06 & $0.35^{* *}$ \\
\hline Juxian & $0.17^{* *}$ & $0.20^{*}$ & -0.01 & 0.10 & $0.40^{* *}$ \\
\hline Sanmenxia & 0.10 & 0.19 & -0.18 & 0.12 & $0.26^{*}$ \\
\hline Zhengzhou & $0.14^{*}$ & 0.21 & -0.12 & 0.17 & $0.30^{*}$ \\
\hline Xuchang & -0.09 & -0.09 & $-0.30^{* *}$ & -0.01 & 0.02 \\
\hline Kaifeng & $0.15^{* *}$ & 0.18 & -0.11 & $0.21^{*}$ & $0.33^{* *}$ \\
\hline Baofeng & 0.04 & 0.01 & $-0.22^{* *}$ & 0.16 & 0.19 \\
\hline Xihua & 0.11 & 0.13 & -0.12 & 0.13 & $0.31^{*}$ \\
\hline Shangqiu & 0.12 & 0.16 & -0.10 & 0.08 & $0.33^{* *}$ \\
\hline Dangshan & $0.25^{* *}$ & $0.30^{* *}$ & 0.01 & $0.22^{*}$ & $0.47^{* *}$ \\
\hline Xuzhou & $0.20^{* *}$ & $0.25^{* *}$ & 0.02 & 0.17 & $0.37^{* *}$ \\
\hline Bozhou & $0.15^{*}$ & 0.15 & -0.09 & 0.18 & $0.34^{* *}$ \\
\hline Suzhou & $0.27^{* *}$ & $0.26^{* *}$ & 0.00 & $0.28^{* *}$ & $0.54^{* *}$ \\
\hline Fuyang & 0.18 & $0.31^{* *}$ & -0.29 & $0.22^{*}$ & $0.47^{* *}$ \\
\hline Whole region & $0.19^{* *}$ & $0.20^{*}$ & -0.01 & $0.16^{*}$ & $0.38^{* *}$ \\
\hline
\end{tabular}

Note: ${ }^{\circ} \mathrm{C} / 10 a{ }^{* *}$ means $\alpha \leq 0.01$ level of significance and ${ }^{*}$ means $\alpha \leq 0.05$ level of significance.

visibly rose after the 1970 s at a rate of $0.37^{\circ} \mathrm{C}$ every 10 years across the entire Region. From 1970 to 1980, temperatures, at all stations, rose with the exception of Yushe. Relatively large increases of $0.6-1.3^{\circ} \mathrm{C}$ over the 10 years were observed at Fuyang, Suzhou, and Xingtai. Average annual temperature for the entire Region increased at a rate of $0.3^{\circ} \mathrm{C}$ over the 10 years. From this data, we can see that while temperature increases in the 1980s in the Lower Yellow River Region slowed down, temperature increases after the 1990s are generally larger than those observed between 1970 and 1990. The average temperature increase rate was $0.98^{\circ} \mathrm{C}$ every 10 years (Figure 4), which shows that the temperature increase in the Lower Yellow River Region after the 1990s is speeding up.

Looking at the trend rates of temperature increase across all seasons, the increase in temperature is most significant in the winter followed by spring, with insignificant increases during autumn. The temperature increase rate during winter was $0.38^{\circ} \mathrm{C}$ every 10 years. For spring and autumn, the rate was $0.20^{\circ} \mathrm{C}$ and $0.16^{\circ} \mathrm{C}$ every 10 years, respectively. The average temperature change trends during the summer over the whole Region are mostly negligible (Figure 5), an observation that confirms the theory that, under global warming, temperatures increase the most during winter and spring. There are significant seasonal differences in temperature changes at each station, with significant warming during the winter at Xingtai, Laoting, Dongying, Longkou, and Suzhou. Their temperature increase rates during the winter are all larger than $0.5^{\circ} \mathrm{C}$ every 10 years. Of these, the temperature increase rate at Xingtai was $0.77^{\circ} \mathrm{C}$ every 10 years with the temperature increase being most significant during the winter (Figure 6). 


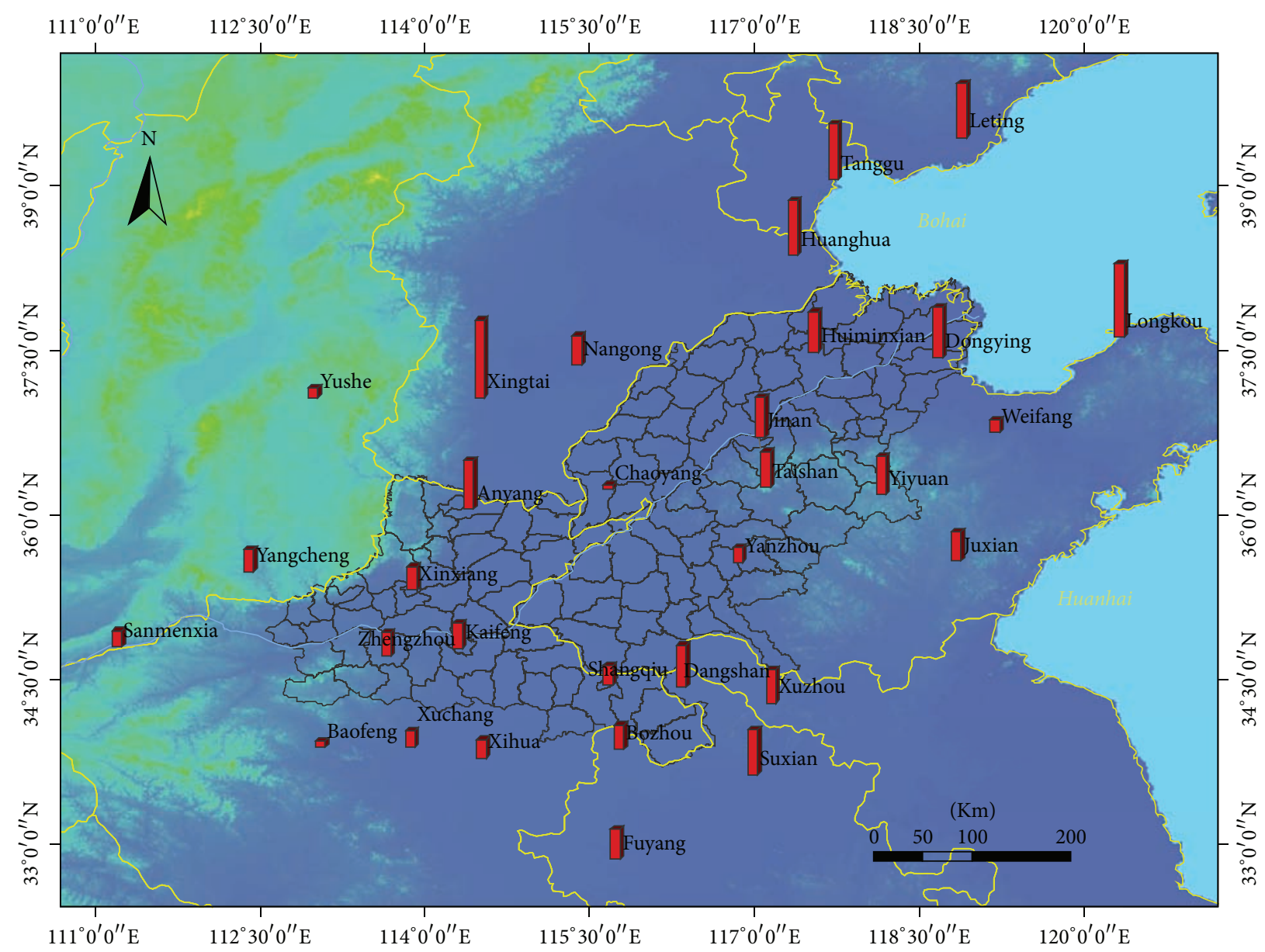

0.23

Figure 3: Trend rates of temperature change at meteorological stations in the Lower Yellow River Region from 1960 to 2001 (unit of measurement ${ }^{\circ} \mathrm{C} / 10$ years).

4.1.3. Spatial Distribution. From 1960 to 2001, the average trend rates for temperature change overall show the special characteristics of being greater in the east than the west and at the coast over inland. The center of the Eastern area is the Yellow River delta, with the average annual temperature rate gradually decreasing outwards. The Yellow River delta has been warming at a rate above $0.34^{\circ} \mathrm{C}$ every 10 years. The central area has a relatively low average temperature trend rate with its center at areas such as Taiqian and Fanxian located in north-eastern Henan province and Western Shandong province, and the rate of warming gradually decreases outward. The trend rates in the western area are larger than those in the central area with the emergence of areas of high increase in Northern Henan. The warming rate is greater than $0.32^{\circ} \mathrm{C}$ every 10 years. The average annual spring temperature trend rates display little change in spatial distribution when compared with the annual average temperature change trend rate. However, the central area's trend rate is negative and shows cooling at a rate of $0.01 \sim 0.07^{\circ} \mathrm{C}$ every 10 years, with the changes in high trend rates the same as annual trend rates.
The warming trend in the summer decreased significantly when compared with the spring and some reduction in regional warming. However, the average trend rate center for summer does not change significantly with the relatively significant warming observed at the Yellow River delta, Northern and Eastern Henan. The average temperature trend rates at the center in autumn did increase, with Taishan Mountain as another warming center. The warming across the entire Region is most apparent in the winter, when the increase rate reached $0.12 \sim 0.58^{\circ} \mathrm{C}$ every 10 years. However, the changes to the high value center location are insignificant (Figure 7).

\subsection{Changes in Precipitation}

4.2.1. Interannual Changes in Precipitation Rate. The total average precipitation rate from 1960 to 2001 in the Lower Yellow River Region was $651.66 \mathrm{~mm}$. However, this rainfall was not distributed evenly across this time period. On the 


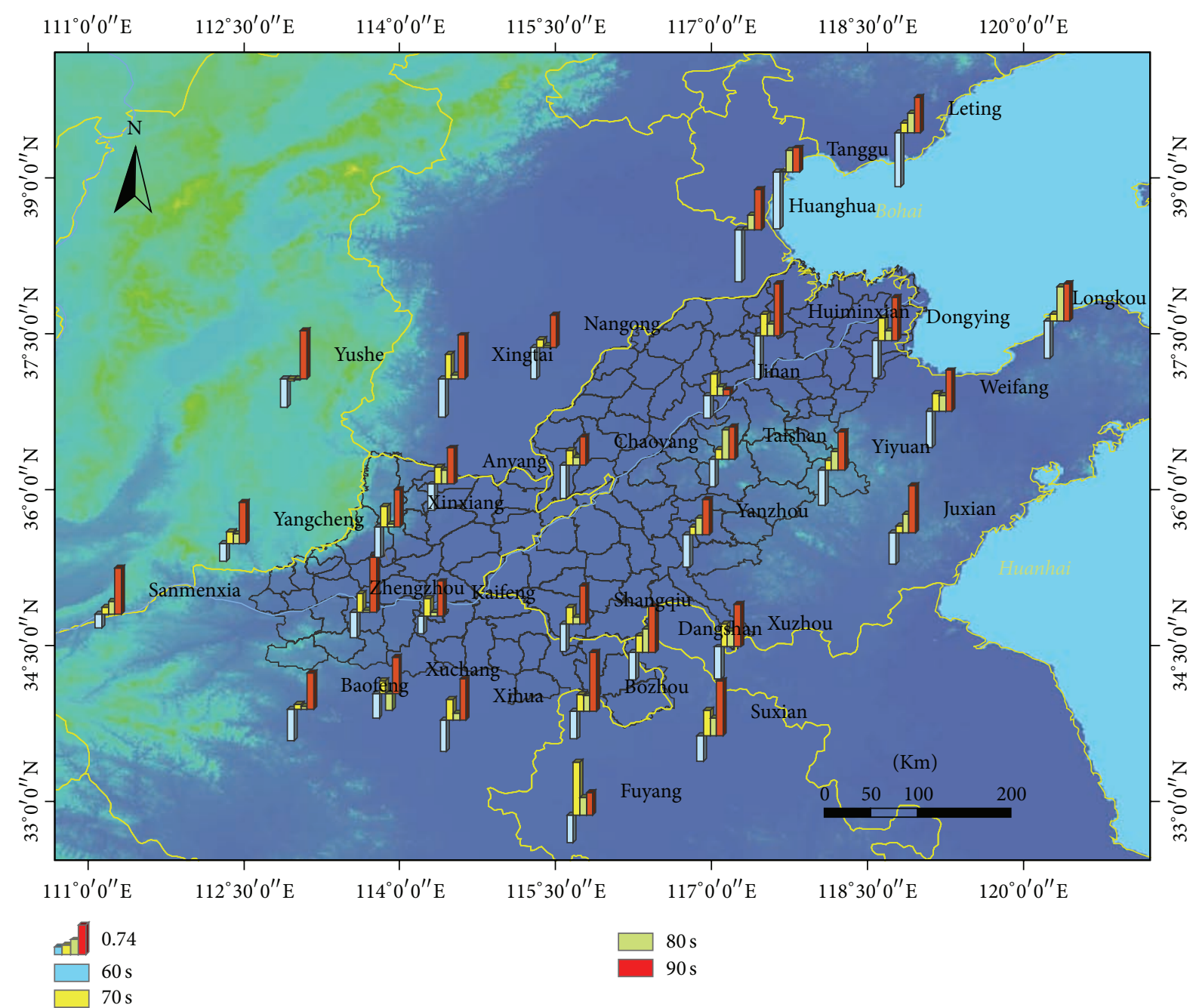

Figure 4: Average temperature change trend rates at each station in the Lower Yellow River Region across different time periods (unit of measurement ${ }^{\circ} \mathrm{C} / 10$ years).

contrary, this precipitation displayed a decreasing trend at a rate of $-11.72 \mathrm{~mm}$ every 10 years. Looking at each decade, the precipitation rate in the Lower Yellow River Region actually increased from 1960 to 1965, with cumulative rising anomalies, while from 1965 to 1970 the precipitation rate continuously dropped. From the 1970s onwards, average annual precipitation mainly decreased with cumulative anomalies dropping as well (Figure 8 ). The precipitation change trend in the summer was basically the same as the average annual precipitation rate, while in the spring the precipitation rate fluctuated widely. There was a cumulative decline in anomaly volatility from 1964 to 1981, while in the 1980s volatility increased again. Then there was a period of continuous decline from 1991 to 1995 . The autumn precipitation rate in the entire Region remained relatively unchanged from 1960 to 1981 before continuously increasing between 1981 and 1985. Afterwards these fluctuations, the trend showed further decline. The winter precipitation rate in the Region trended downwards from 1960 to 1978 . It remained unchanged from
1979 to 1988 before increasing in the 1990 s, where the rate turned upwards (Figure 9).

4.2.2. Changes in Interannual Precipitation Trend Rate. All of the stations, with the exception of Xuchang, Kaifeng, Baofeng, Xihua, Xuzhou, Bozhou, and Fuyang, showed negative precipitation trend rates (Table 2 ). This reveals that the precipitation rate is decreasing in most areas in the Region, especially in the areas of Dongying, Chaoyang, Huanghua, and Juxian where the rates are $-39.86 \mathrm{~mm}$, $-41 \mathrm{~mm},-53.2 \mathrm{~mm}$, and $-54 \mathrm{~mm}$ every 10 years, respectively. The most significant areas of average annual precipitation rate increase are Fuyang and Xihua at $37.45 \mathrm{~mm}$ and $40.1 \mathrm{~mm}$ every 10 years, respectively. The precipitation rate in the Lower Yellow River Region mainly decreased between 1960 and 1980 at a rate of $-38.9 \mathrm{~mm}$ every 10 years. Although the stations at Zhengzhou, Kaifeng, Baofeng, Xihua, and Shangqiu posted increasing precipitation rates, all the other 

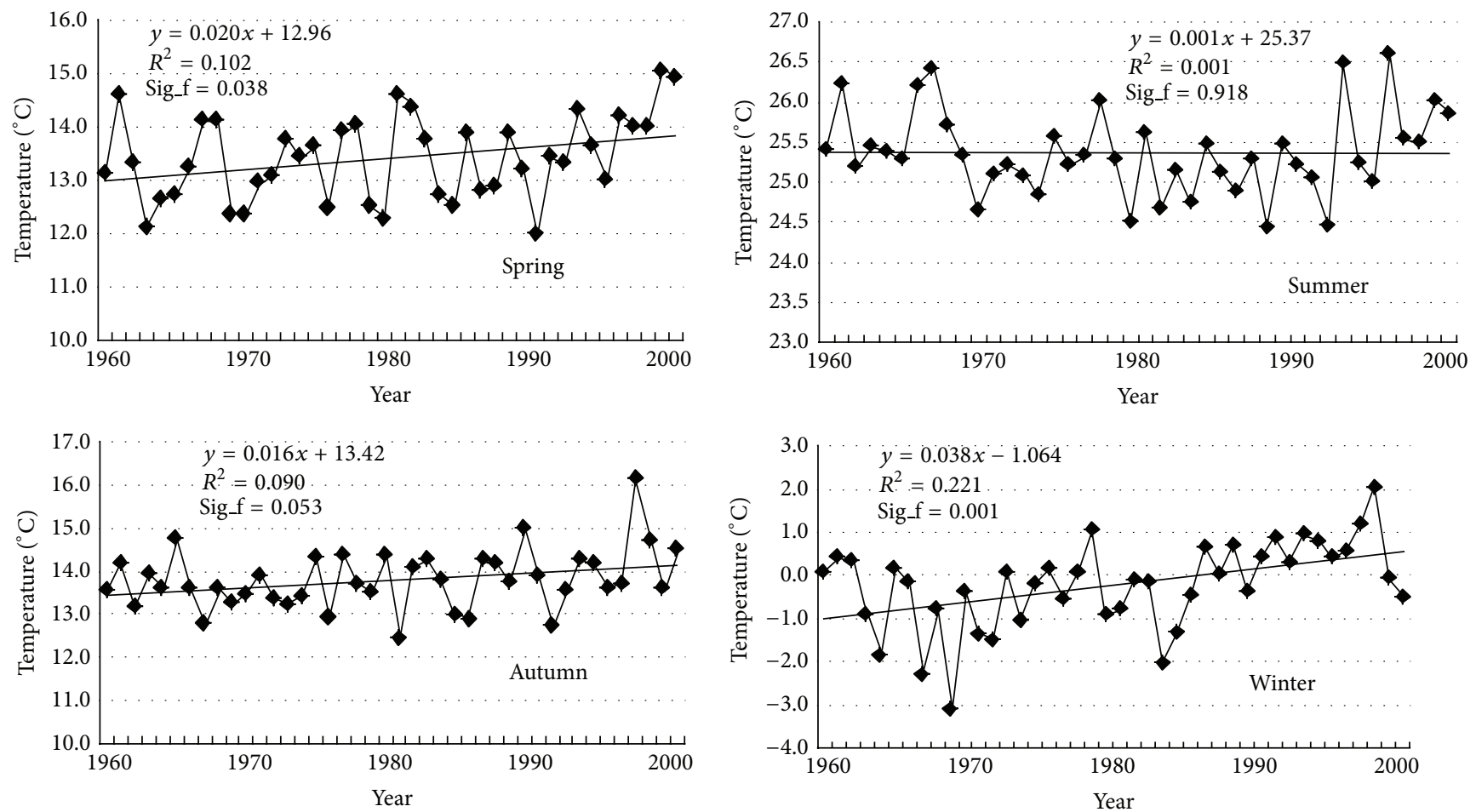

FIGURE 5: Interannual temperature change trend rates in the Lower Yellow River Region.

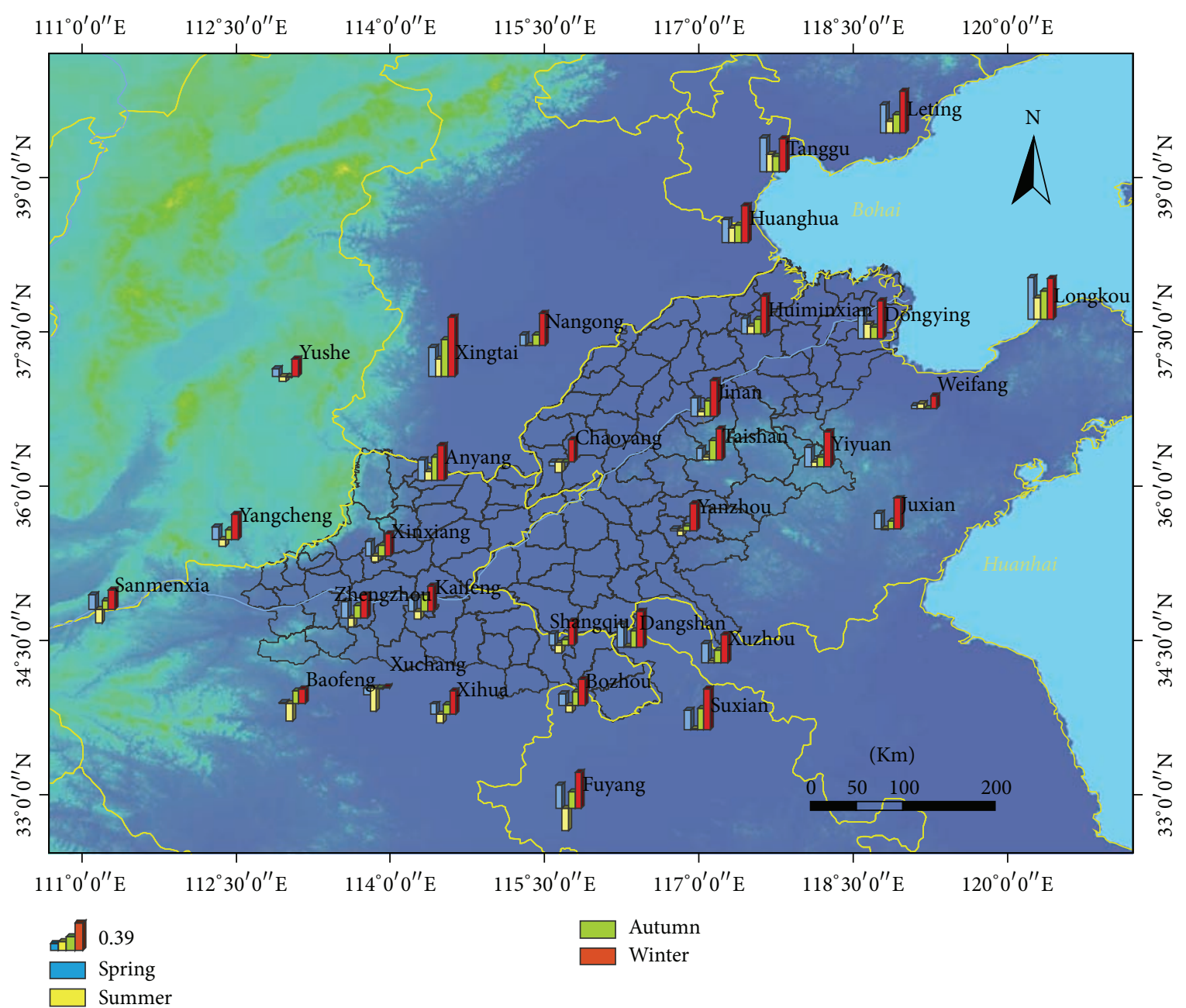

FIGURE 6: Average temperature change trend rates at each station in the Lower Yellow River Region (unit of measurement ${ }^{\circ} \mathrm{C} / 10$ years). 


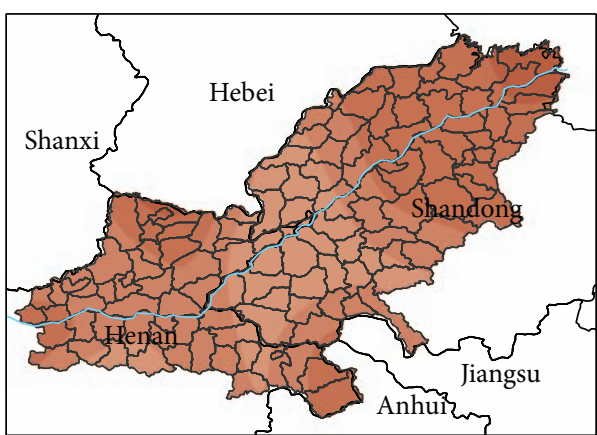

(a) Annual

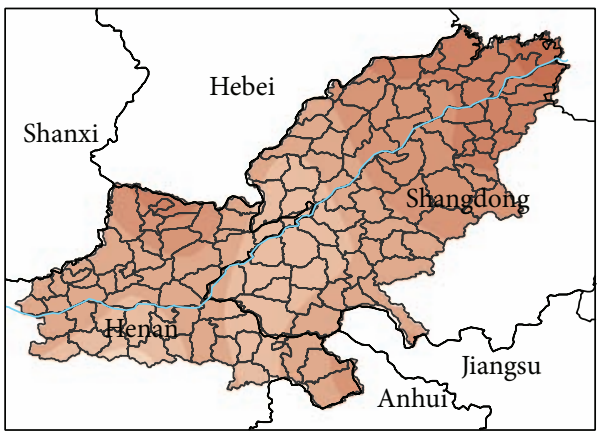

(c) Summer

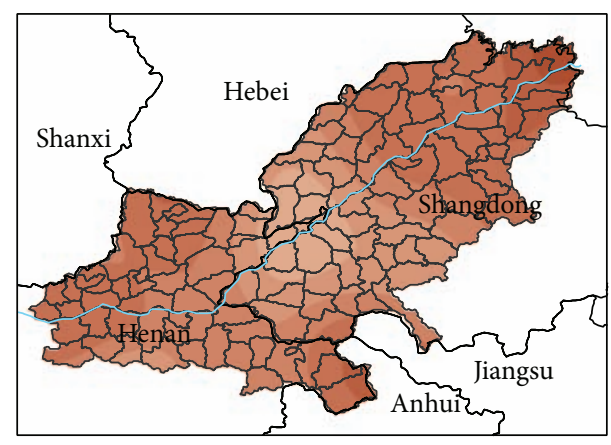

(b) Spring

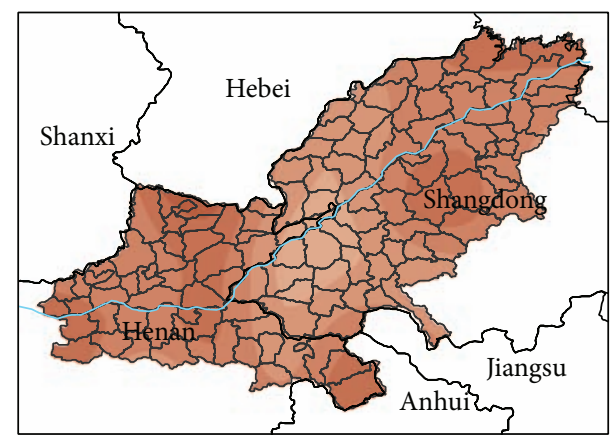

(d) Autumn

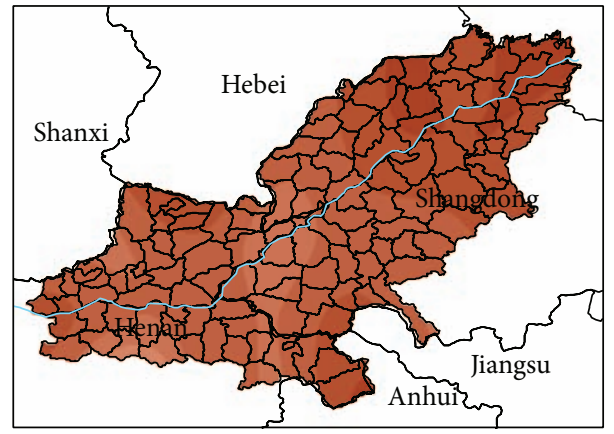

Temperature slope

$\left({ }^{\circ} \mathrm{C} / 10 \mathrm{a}\right)$

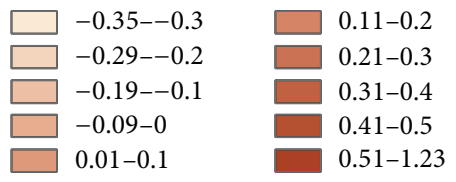

(e) Winter

Figure 7: Spatial Distribution of annual temperature trend rates in the Lower Yellow River Region from 1960 to 2001.

stations had decreasing precipitation rates, with Juxian having the most significant decrease. The precipitation rate for the whole area generally increased from 1981 to 2001, but the trend rate was only $7.9 \mathrm{~mm}$ every 10 years, which is much smaller than the rate of decrease seen between 1961 and 1980. Twelve stations, including Yushe, Yangcheng, Laoting, and Tanggu, had decreasing precipitation rates, while the other nineteen all had increasing precipitation rates (Figure 10).

The seasonal precipitation rate for each of the stations reveals that the area's precipitation rates during the spring and winter had increasing trends, while autumn and summer had decreasing trends. The increasing trend rate in the winter was much greater than the spring rate, and the decrease in the summer was greater than in autumn. The seasonal annual average precipitations trend rates were $1.13 \mathrm{~mm},-13.9 \mathrm{~mm}$, $-7.6 \mathrm{~mm}$, and $8.66 \mathrm{~mm}$ every 10 years, respectively.

4.2.3. Spatial Distribution. The precipitation trend rates in the Lower Yellow River Region between 1960 and 2001 also showed significant spatial differences. With the exception of 


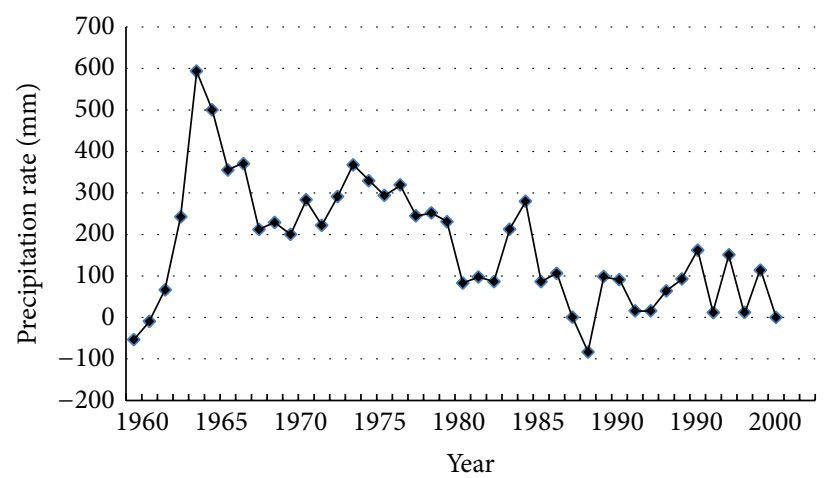

FIGURE 8: Cumulative average annual precipitation rate anomalies in the Lower Yellow River Region from 1960 to 2001.
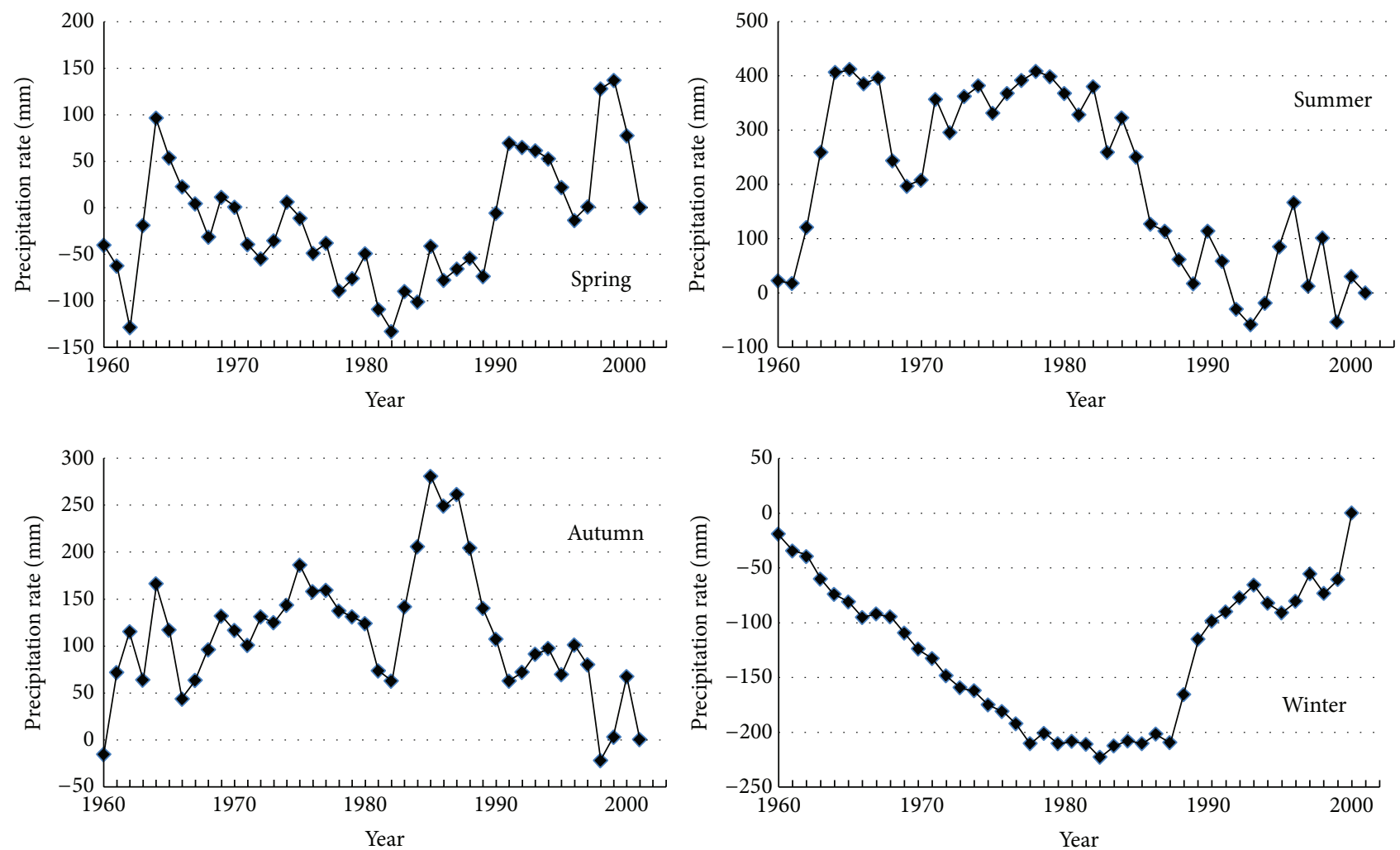

FIgURE 9: Cumulative precipitation rate anomalies in all seasons in the Lower Yellow River Region from 1960 to 2001.

the Zhengzhou and Kaifeng areas in central Henan province, all other areas showed decreasing trends. The two centers in the area bordering North-Eastern Henan and Shandong provinces as well as Taishan Mountain around Chaoyang station, Shen, Yanggou, and Taiqian counties have the lowest precipitation trend rates at greater than $37 \mathrm{~mm}$ per 10 years. The annual precipitation trend rate for Taishan Mountain is between $4.8 \mathrm{~mm}$ and $5.8 \mathrm{~mm}$ every 10 years, and the rate gradually decreases outwards. Looking at the seasonal precipitation trend rates, we can see that summer's trend rate is practically identical to the annual trend rate. The spring trend rate has a high value center at the Taishan Mountain area, with the rate between $8 \mathrm{~mm}$ and $10 \mathrm{~mm}$ every
10 years, and, again, the rate gradually decreases outwards. The central southern area of the Region had a smaller trend rate decreasing between $15 \mathrm{~mm}$ and $22 \mathrm{~mm}$ every 10 years. The autumn trend rate in the area was negative and decreased between $2.6 \mathrm{~mm}$ and $19 \mathrm{~mm}$ every 10 years. The rate of decrease is greater in the east than the west and gradually decreases westwards with a low value center appearing in North-Eastern Henan and Western Shandong province. The winter precipitation trend rate in this area showed increasing trends. The spatial distribution shows that the increasing rate lessens from south to north with the Yellow River as a boundary, and a high value center appears at Taishan Mountain (Figure 11). 


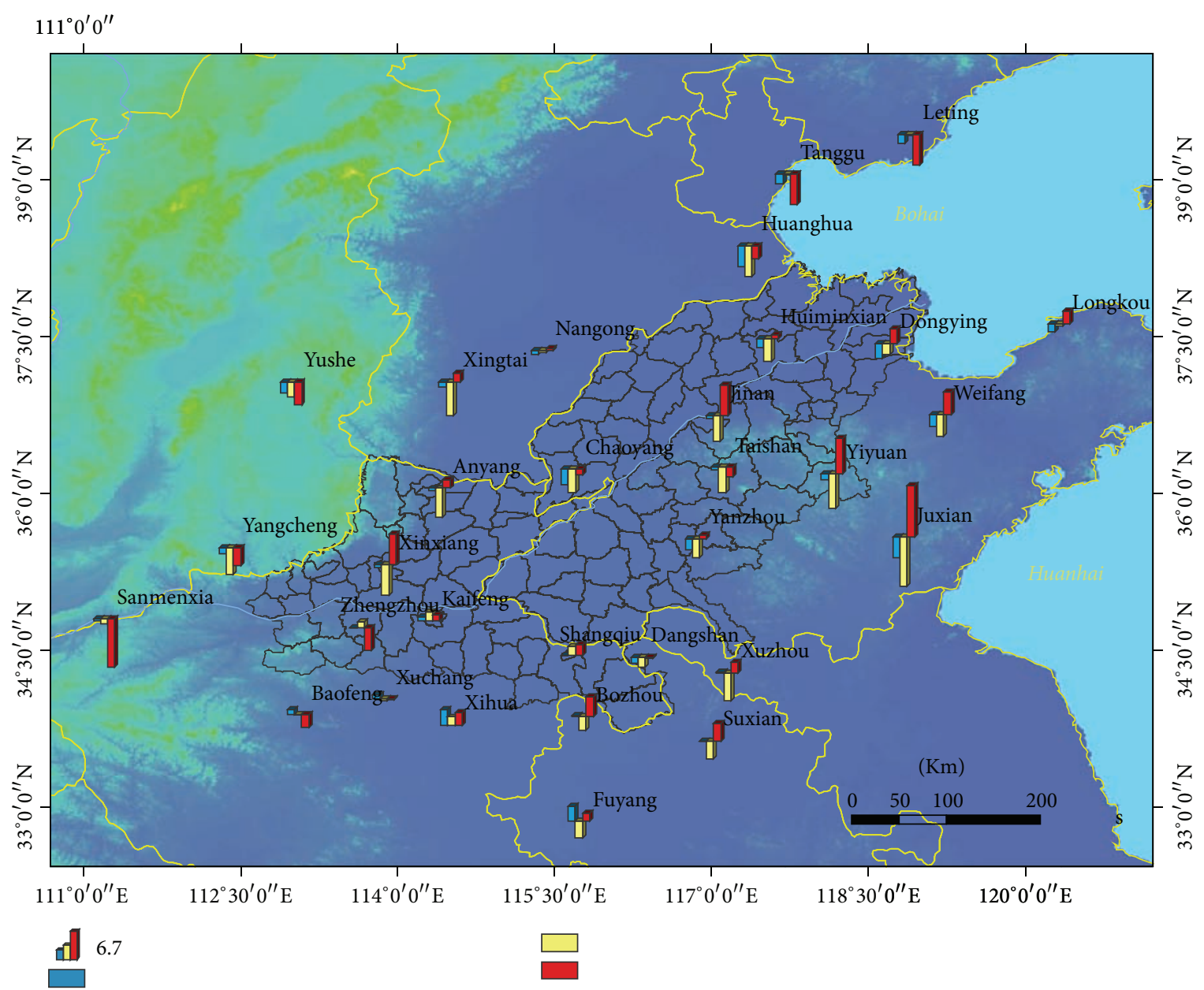

Figure 10: Average annual precipitation trend rates at stations in the Lower Yellow River Region from 1960 to 2001 (unit of measurement $\mathrm{mm}$ /year).

4.2.4. Precipitation Variance. The precipitation rate variance is the change in precipitation rate over a period of time (year, season, or month) and is the relative degree of dispersion in precipitations $[10,11]$. It can show whether the precipitation in a region is consistent or not. Areas with low variance have consistent precipitation; this is calculated with the following formula:

$$
V=\sqrt{\frac{(1 / n) \sum_{i=1}^{n}\left(x_{i}-\bar{x}\right)^{2}}{\bar{x}}}
$$

In the equation, $i=1,2,3, \ldots, n$ represents the time sequence for calculating precipitation variance, $x_{i}$ represents the precipitation rate in $i$ years in the Region, and $\bar{x}$ represents the average precipitation rate in the Region.

The precipitation variation in the Lower Yellow River Region from 1960 to 2001 was 0.27 , which means that the annual precipitation rate is inconsistent. The precipitation variation at the Anyang, Xingtai, Tanggu, and Huanghua stations was quite high from 0.32 to 0.36 . The precipitation variance was lowest at Xuzhou at 0.19, which means that the rate is quite consistent. Figure 11 shows the precipitation variance distribution of each station in the Lower Yellow River Region. From this figure, we can see that the precipitation variance was greater in areas of higher latitudes than lower latitudes. The average interannual precipitation rate distribution has the opposite relationship (Figure 12).

Looking at each of the seasons, we can see that the seasonal variation in precipitation is relatively large, which shows that the Region has inconsistent seasonal precipitation. The summer precipitation variance was 0.37 , the spring and fall variances were 0.58 and 0.52 , and the winter variance was 1.09. The summer variance is the smallest and the winter the largest, which is due to the extremely uneven precipitation over time in the Lower Yellow River Region, which is mainly concentrated in the summer months.

4.3. Integrated Temperature and Precipitation Trends. According to the increasing/decreasing trends for temperature and precipitation, we can categorize the Region's hydrothermal conditions as warm and wet, warm and dry, cold and wet, and cold and dry. We can find the integrated temperature and precipitation trends for each station in the Lower Yellow 


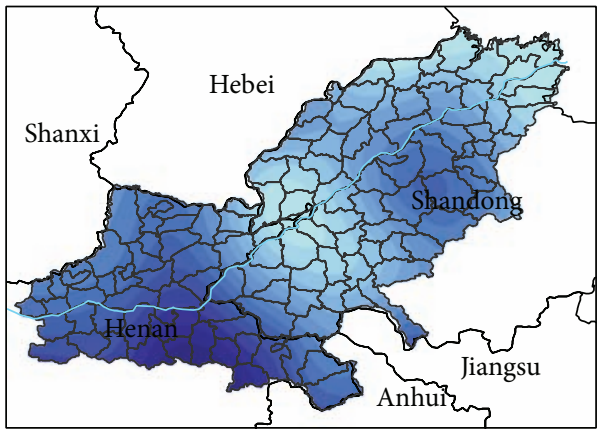

(a) Annual

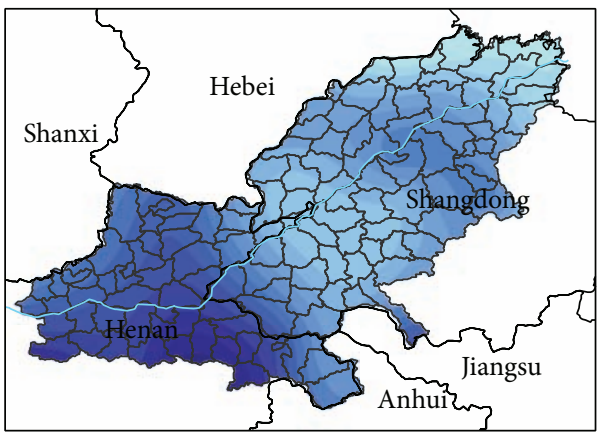

(c) Summer

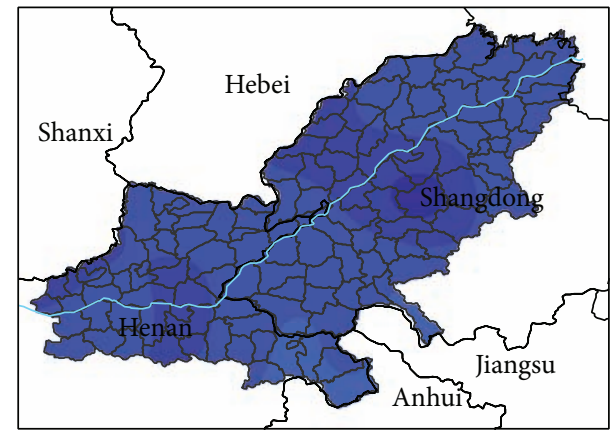

(b) Spring

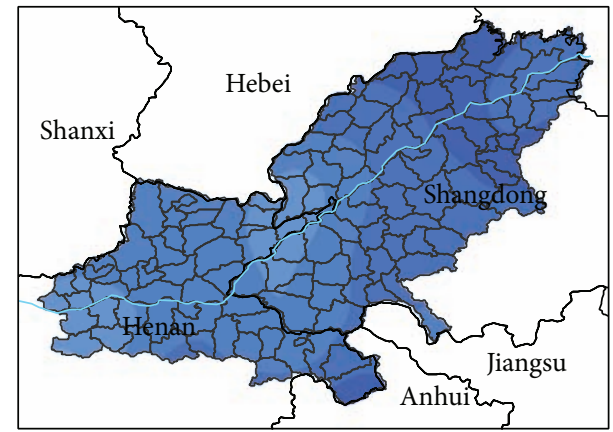

(d) Autumn

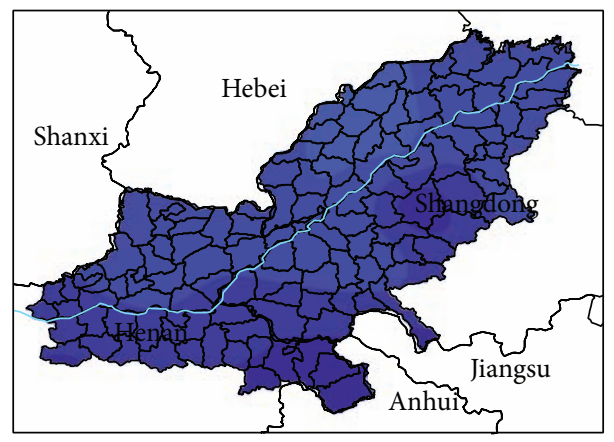

Precipitation slope $(\mathrm{mm} / \mathrm{a})$

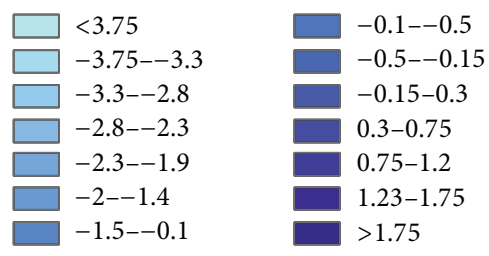

(e) Winter

FIGURE 11: Spatial distribution of precipitation trend rates in the Lower Yellow River Region from 1960 to 2001.

River Region from the average annual temperature and precipitation trend rates.

As we can see from Figure 13 that the integrated temperature and precipitation trend in the areas of the Lower Yellow River Region were mainly warm and dry. Of the stations included in this study, 24 showed warm and dry trends, a number comprising $77 \%$ of the total. Kaifeng, Xihua, Xuzhou, Bozhou, and Fuyang showed a warm and wet trend, accounting for $20 \%$ of the total number of sites, while Xuchang was cold and wet. 


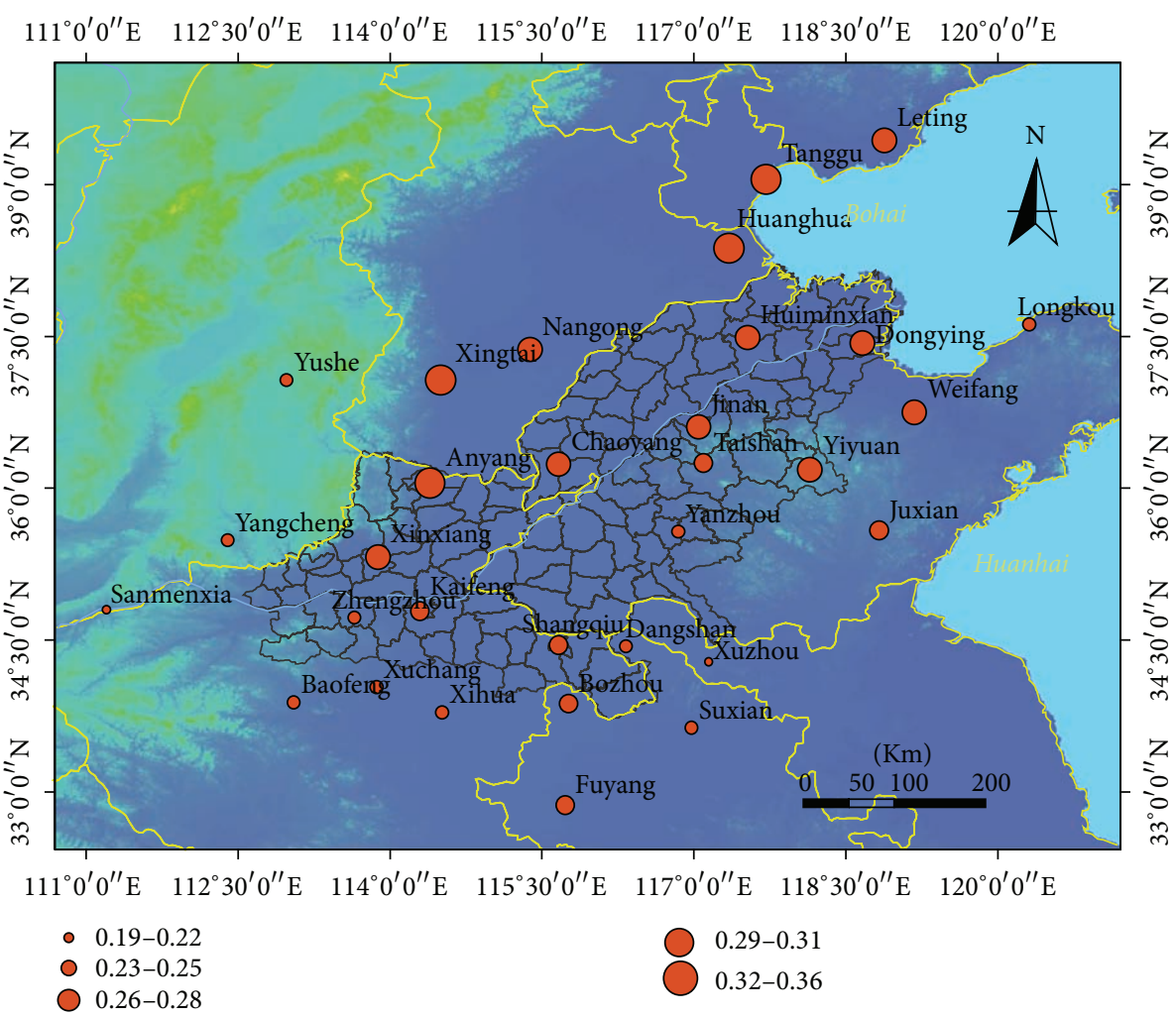

(a) Precipitation variance

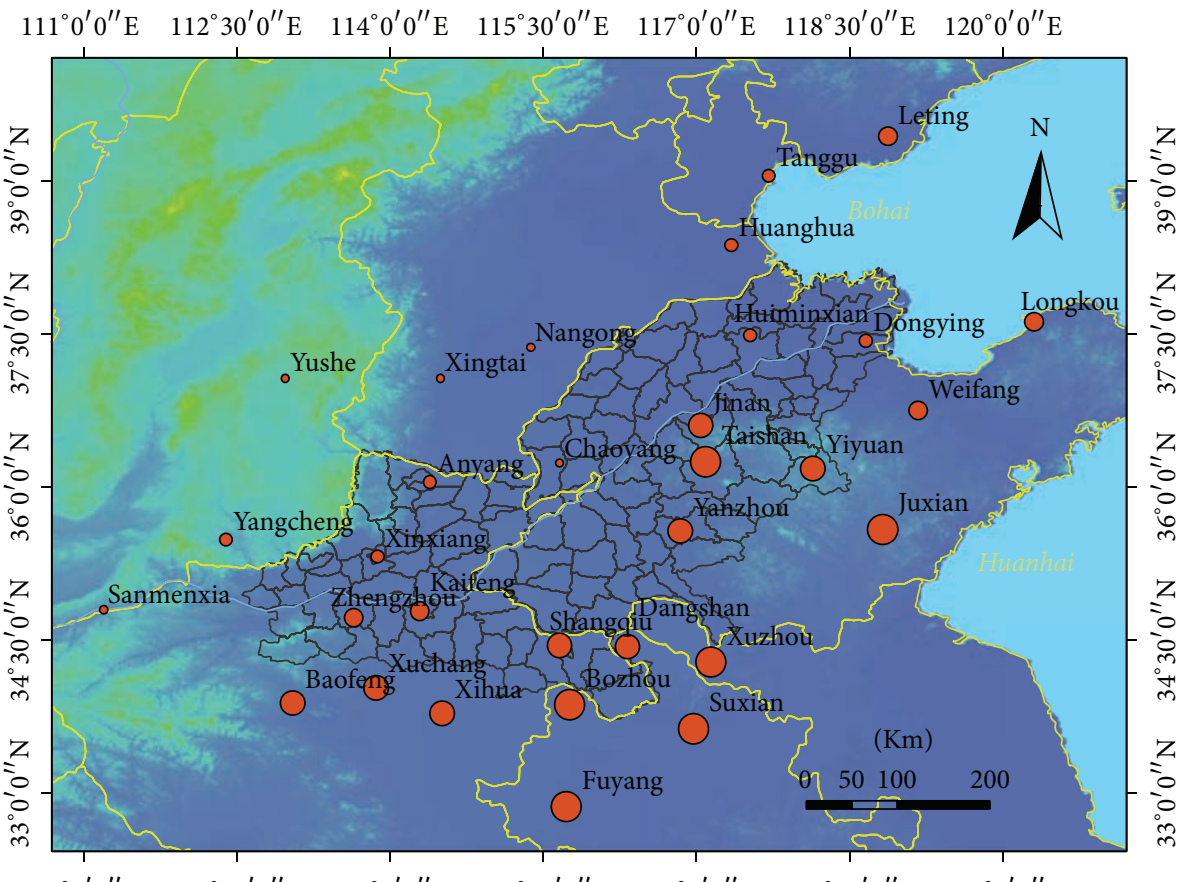

$111^{\circ} 0^{\prime} 0^{\prime \prime} \mathrm{E} \quad 112^{\circ} 30^{\prime} 0^{\prime \prime} \mathrm{E} \quad 114^{\circ} 0^{\prime} 0^{\prime \prime} \mathrm{E} \quad 115^{\circ} 30^{\prime} 0^{\prime \prime} \mathrm{E} \quad 117^{\circ} 0^{\prime} 0^{\prime \prime} \mathrm{E} \quad 118^{\circ} 30^{\prime} 0^{\prime \prime} \mathrm{E} \quad 120^{\circ} 0^{\prime} 0^{\prime \prime} \mathrm{E}$

Precipitation $(\mathrm{mm})$

- 465.4-533.9

$611.1-736.9$

- $534.0-577.4$

$737.0-1011.8$

○ $577.5-611.0$

(b) Annual average precipitation rate

FIGURE 12: Distribution of annual precipitation variation and average annual precipitation rate in the Lower Yellow River Region from 1960 to 2001 . 


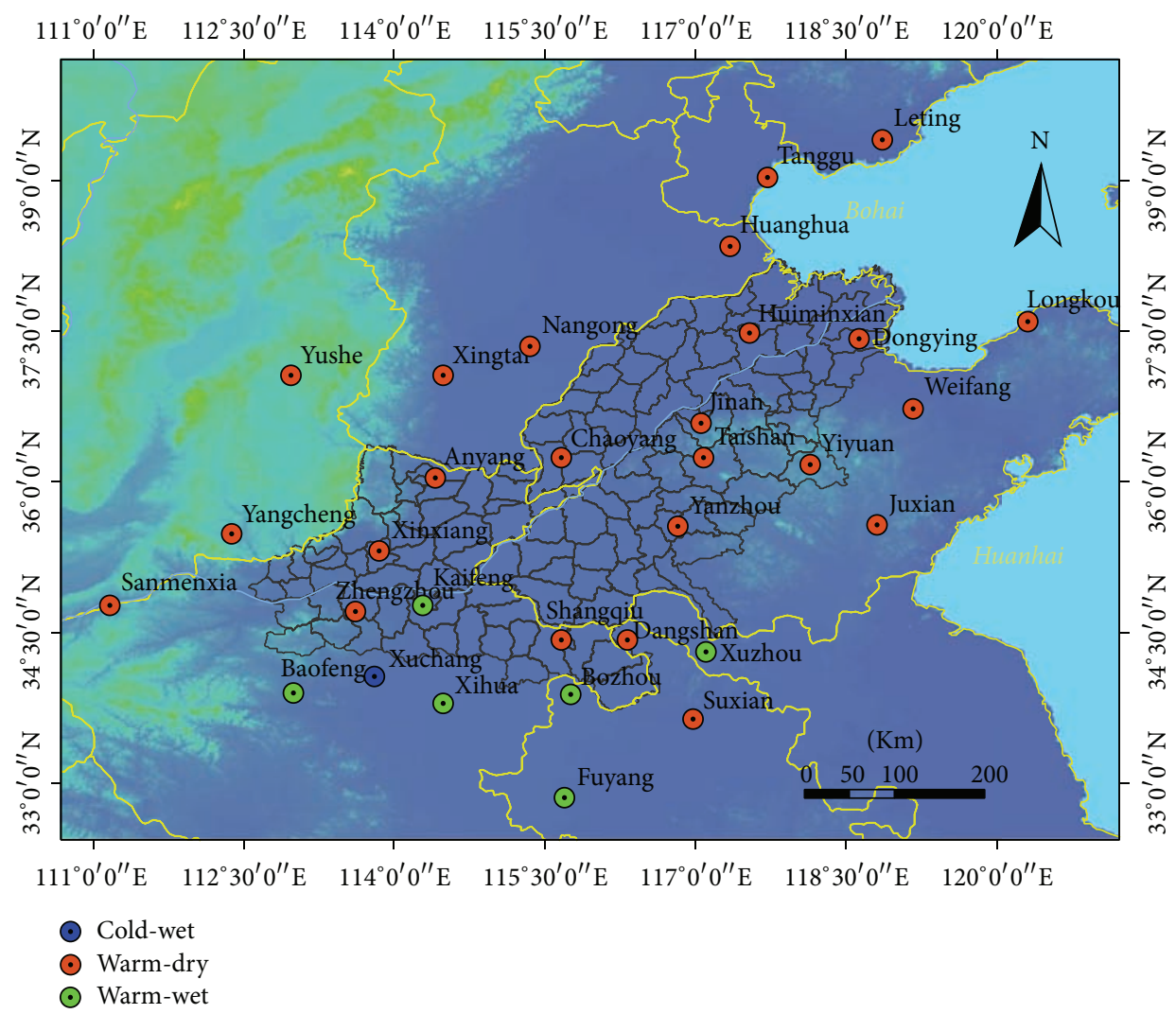

FIGURE 13: Integrated temperature and precipitation trends at stations in the Lower Yellow River Region.

\section{Conclusion}

(1) The average annual temperature in the Lower Yellow River Region showed increasing trends from 1961 to 2001. In the 1960s-1980s, there were significant increases at the rate of 0.98 degrees every 10 years. This is the same conclusion as Tan Fangying and Jones PD's. North China before the mid-1980s experienced a low temperature period then faced continued warming beginning in 1988 [12, 13]. The average temperature trend rate in northeast was greater than that found in southwest, following the overall characteristic of distribution found in this study, namely, warming in the northeast greater than the southwest. In the Lower Yellow River Region from 1960 to 2001, the temperature difference between north and south showed a decreasing trend.

From 1960 to 2001, winter temperatures in the Lower Yellow River Region showed a significant trend of increase, revealing a clear warming trend, followed by spring and autumn [5]. Summer temperatures did not change significantly, confirming the context of global warming, with winter and spring warming the most obvious in this conclusion.

(2) In the Lower Yellow River Region, from 1960 to 2001, the average annual rainfall showed a declining trend at a rate of $-11.7 \mathrm{~mm} / 10$ years. Between 1960 and 1965, annual precipitation continued to increase, and after the 1970s, the annual precipitation remained unchanged. Beginning in the late 1980s, annual precipitation showed a decreasing trend, and the cumulative decline entered an anomalous fluctuating state.

The Lower Yellow River Region precipitation variability was $27 \%$, yearly precipitation fluctuated more intensely, and precipitation instability and variability both showed gradual increases from south to north. Summer rainfall is more concentrated making the precipitation decreasing trend the most obvious then, followed by autumn, while,in spring and winter, precipitation has a weak increase. In winter, the precipitation increasing trend is much larger than the spring. Its trend rate was $8.6 \mathrm{~mm}$ every 10 years; this increase is less than the decrease observed in summer. In the context of global climate change, precipitation patterns throughout the North China plains coincide with global trends [12, 14].

(3) Between 1960 and 2001, the Lower Yellow River Region was dominated by warm and dry sites, which accounted for $77 \%$ of the total. Between 1960 and 1980, the Lower Yellow River Region was dominated mainly by dry cold. Around the 1980s, average temperatures continued to rise, changing the Region's cold dry weather conditions to warmer and drier ones. Ma [15-18] and Yang et al. [19] 
TABLE 2: Annual precipitation trend, precipitation trend in spring, precipitation trend in summer, precipitation trend in autumn, precipitation trend in winter, and their significances.

\begin{tabular}{|c|c|c|c|c|c|}
\hline Station & Annual trend & Trend in spring & Trend in summer & Trend in autumn & Trend in winter \\
\hline Yushe & -29.76 & 4.25 & $-28.00^{*}$ & -10.39 & $4.38^{* *}$ \\
\hline Xingtai & -12.93 & 0.61 & -12.02 & -5.81 & $4.29^{* *}$ \\
\hline Anyang & -7.30 & 1.55 & -3.28 & -11.69 & $6.12^{* *}$ \\
\hline Yangcheng & -15.43 & 6.16 & -18.39 & -11.92 & $8.71^{* *}$ \\
\hline Xinxiang & -6.97 & 2.76 & -2.40 & -11.63 & $4.30^{* *}$ \\
\hline Leting & -24.63 & 6.45 & $-39.70^{*}$ & 5.40 & $3.22^{* *}$ \\
\hline Tanggu & -25.55 & 7.90 & -38.59 & 2.17 & $2.97^{* *}$ \\
\hline Huanghua & $-53.22^{*}$ & 3.57 & $-59.45^{* *}$ & -1.43 & $4.09^{* *}$ \\
\hline Nangong & -9.30 & 5.74 & -14.96 & -5.16 & $5.07^{* *}$ \\
\hline Huiminxian & -24.28 & 0.62 & -25.33 & -4.70 & $5.13^{* *}$ \\
\hline Dongying & -39.86 & 0.09 & $-35.90^{*}$ & -8.10 & $4.05^{*}$ \\
\hline Longkou & -20.03 & -3.31 & -11.08 & $-14.49^{*}$ & $8.85^{* *}$ \\
\hline Chaoyang & $-40.98^{*}$ & 2.10 & -31.06 & $-15.49^{*}$ & $3.47^{*}$ \\
\hline Jinan & -9.09 & 5.25 & -13.07 & -6.67 & $5.40^{* *}$ \\
\hline Taishan & -8.07 & 10.04 & -24.69 & -7.78 & $14.36^{* *}$ \\
\hline Yiyuan & -13.61 & -0.51 & -13.59 & -5.77 & $6.25^{* *}$ \\
\hline Weifang & -31.12 & -3.45 & -35.87 & 1.20 & $7.00^{* *}$ \\
\hline Yanzhou & -29.11 & 1.41 & -30.45 & -6.15 & $6.08^{* *}$ \\
\hline Juxian & $-54.03^{*}$ & 0.56 & $-49.40^{*}$ & -12.02 & $6.83^{* *}$ \\
\hline Sanmenxia & -4.63 & -1.52 & 0.94 & -9.57 & $5.51^{* *}$ \\
\hline Zhengzhou & -1.09 & 0.97 & 2.18 & -14.63 & $10.39^{* *}$ \\
\hline Xuchang & 10.72 & 2.78 & 6.46 & -9.60 & $11.08^{* *}$ \\
\hline Kaifeng & 9.27 & 3.83 & 7.19 & -10.63 & $8.88^{* *}$ \\
\hline Baofeng & 13.19 & -0.33 & 19.64 & -19.75 & $13.64^{* *}$ \\
\hline Xihua & 40.13 & 0.78 & 32.67 & -7.15 & $13.83^{* *}$ \\
\hline Shangqiu & -0.92 & -2.13 & 0.49 & -12.38 & $13.09^{* *}$ \\
\hline Dangshan & -16.05 & -0.88 & -20.89 & -7.79 & $13.52^{* *}$ \\
\hline Xuzhou & 1.38 & -4.59 & 1.64 & -11.27 & $15.60^{* *}$ \\
\hline Bozhou & 3.43 & -2.88 & -1.10 & -6.27 & $13.69^{* *}$ \\
\hline Suzhou & -1.02 & -2.91 & -12.73 & -1.66 & $16.28^{* *}$ \\
\hline Fuyang & 37.45 & -9.78 & 20.17 & 4.85 & $22.23^{* *}$ \\
\hline Whole region & -11.72 & 1.13 & -13.89 & -7.62 & $8.66^{* *}$ \\
\hline
\end{tabular}

Note: $\mathrm{mm} / 10 a{ }^{* *}$ means $\alpha \leq 0.01$ level of significance and ${ }^{*}$ means $\alpha \leq 0.05$ level of significance.

research also showed that, between 1951 and 2004, China's northern Region was dominated by a trend of drought. Between 1980 and 2000, the Lower Yellow River Region experienced a prolonged drought once every hundred years, between 1980 and 2000, rainfall in the Region continued to decrease independent of the historical drought trend, while the 1980s also saw the beginning of sustained temperature rises. These trends combined to produce the expansion of regional aridity.

\section{Conflict of Interests}

The authors declare that there is no conflict of interests regarding the publication of this paper.

\section{Acknowledgments}

This project is funded with support from National Natural Science Foundation of China under Project 41371525, National Basic Research Program of China (973 Program) 2012CB955800 (2012CB955804), China Postdoctoral Science Foundation funded Project (2012M521390 and 2013T60696), and Scientific Research Foundation for Returned Scholars 2013(693) and 2013B065.

\section{References}

[1] IPCC, Climate Change 2007: Synthesis Report, Intergovernmental Panel on Climate Change, 2007. 
[2] Y. H. Ding, G. Y. Ren, G. Y. Shi et al., "National assessment report of climate change (I): climate change in China and its future trend," Advances in Climate Change Research, vol. 2, no. 1, pp. 3-8, 2006.

[3] D. Qin, Z. L. Cheng, and Y. Luo, "Updated understanding of climate change sciences," Advances in Climate Change Research, vol. 3, no. 2, pp. 63-73, 2007.

[4] T. Yang, S. Rao, and D. Chen, "Analysis of the characteristics of temperature and precipitation changes in the Yellow River basin since 1951," Yellow River, vol. 290, no. 10, pp. 78-79, 2009.

[5] Z. Li, Y. He, H. Xin et al., "Spatio-temporal variations of temperature and precipitation in Mts. Hengduan region during 1960-2008," Acta Geographica Sinica, vol. 65, no. 5, pp. 563-579, 2010.

[6] China Meteorological Administration, Climate and Environment in China, China Meteorological Press, Beijing, China, 2006.

[7] B. Ye, C. Li, D. Yang, Y. Ding, and Y. Shen, "Variation trend of precipitation and its impact on water resources in China during last 50 years (I): annual variation," Journal of Glaciology and Geocryology, vol. 26, no. 5, pp. 587-584, 2004.

[8] J. Liu, M. Fan, H. Zhang, and S. Zhao, "The Yellow River basin climate change characteristics and trend," in Proceeding of the Symposium of New Development of Hydrological Technology in China, vol. 6, pp. 213-218, 2012.

[9] Z. Hao, J. Zheng, and Q. Ge, "Precipitation cycles in the middle and lower Yellow River," Acta Geographica Sinica, vol. 62, no. 5, pp. 537-544, 2007.

[10] G. Liu and H. Lu, "Basic characteristics of major climatic factors on Qinghai-Tibet Plateau in recent 45 years," Acta Geographica Sinica, vol. 29, no. 12, pp. 2281-2288, 2010.

[11] L. Feng and S. Zheng, "Variability of precipitation and its deviation in China," Scientia Geographica Sinica, vol. 6, no. 2, pp. 101-109, 1986.

[12] F. Tan, J. Wang, and Y. Song, "Characteristics of climate change in the North China plain for recent 45 years," Meteorological Monthly, vol. 36, no. 5, pp. 40-45, 2010.

[13] P. D. Jones, S. C. B. Raper, R. S. Bradley, H. F. Diaz, P. M. Kelly, and T. M. L. Wigley, "Northern Hemisphere surface air temperature variations: 1851-1984," Journal of Climate \& Applied Meteorology, vol. 25, no. 2, pp. 161-179, 1986.

[14] H. Zhang and L. Feng, "Characteristics of spatio-temporal variation of precipitation in North China in recent 50 years," Journal of Natural Resources, vol. 25, no. 2, pp. 270-279, 2010.

[15] Z. Ma and C. Fu, "Some evidence of drying trend over northern China from 1951 to 2004," Chinese Science Bulletin, vol. 51, no. 23, pp. 2913-2925, 2006.

[16] Z. Ma and C. Fu, "Facts about global aridification in the second half of the 20th centuary and their links with large-scale background," Science in China D, vol. 37, no. 2, pp. 222-233, 2007.

[17] Z. Ma, C. Fu, X. Ren, and C. Yang, "Trend of annual extreme temperature and Its relationship to regional warming in Northern China," Acta Geographica Sinica, vol. 58, supplement 1, pp. 11-20, 2003.

[18] Z. Ma, G. Huang, W. Gan, and M. Chen, "Multi-scale temporal characteristics of the dryness/wetness over Northern China during the last century," Chinese Journal of Atmospheric Sciences, vol. 29, no. 5, pp. 671-681, 2005.

[19] Z. Yang, H. Yang, X. Gu, X. You, and J. Jiang, "Climatic background analysis of flow-break episode of lower reaches of Yellow River in recent years," Acta Meteorologica Sinica, vol. 55, no. 6, pp. 751-758, 2000. 

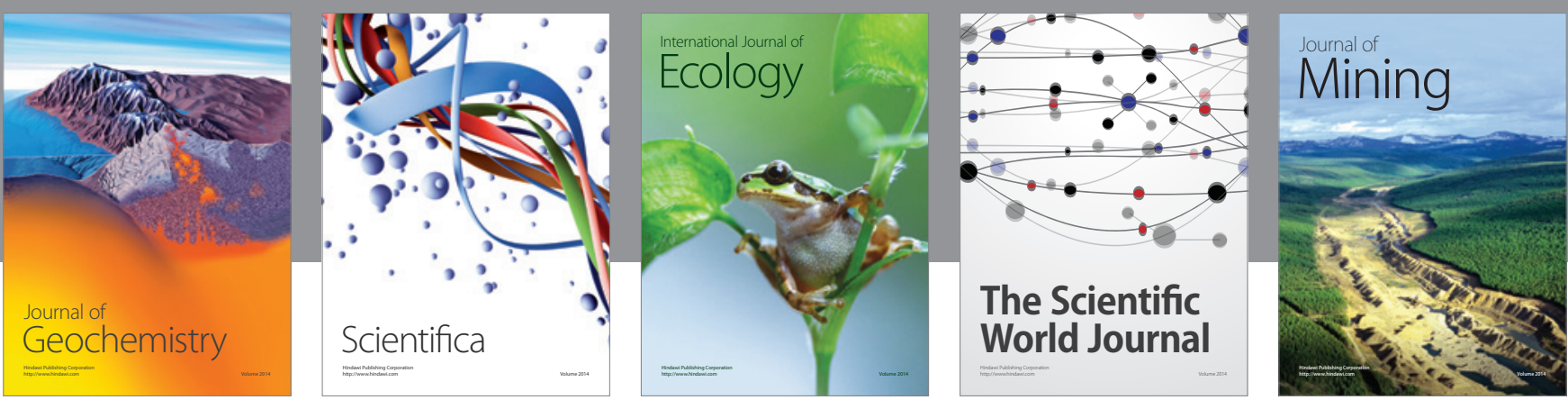

The Scientific World Journal
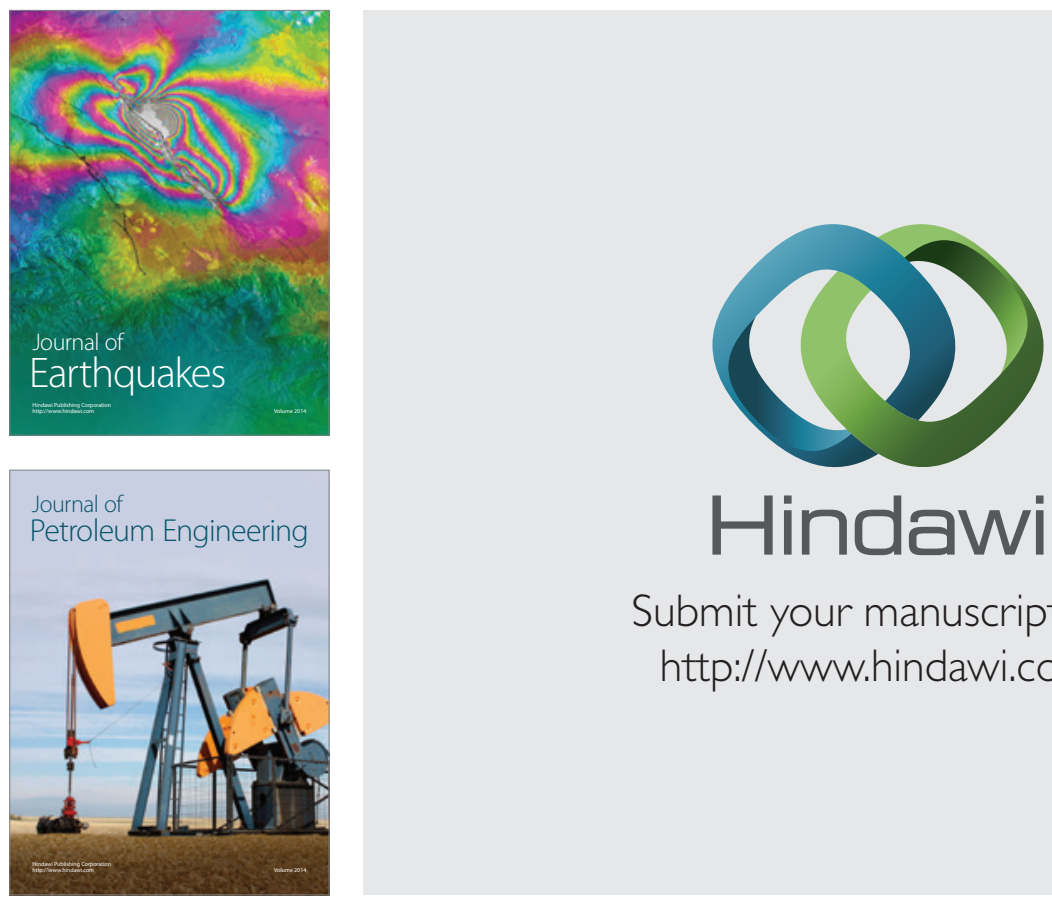

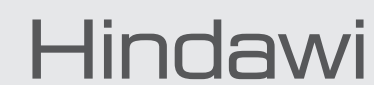

Submit your manuscripts at

http://www.hindawi.com
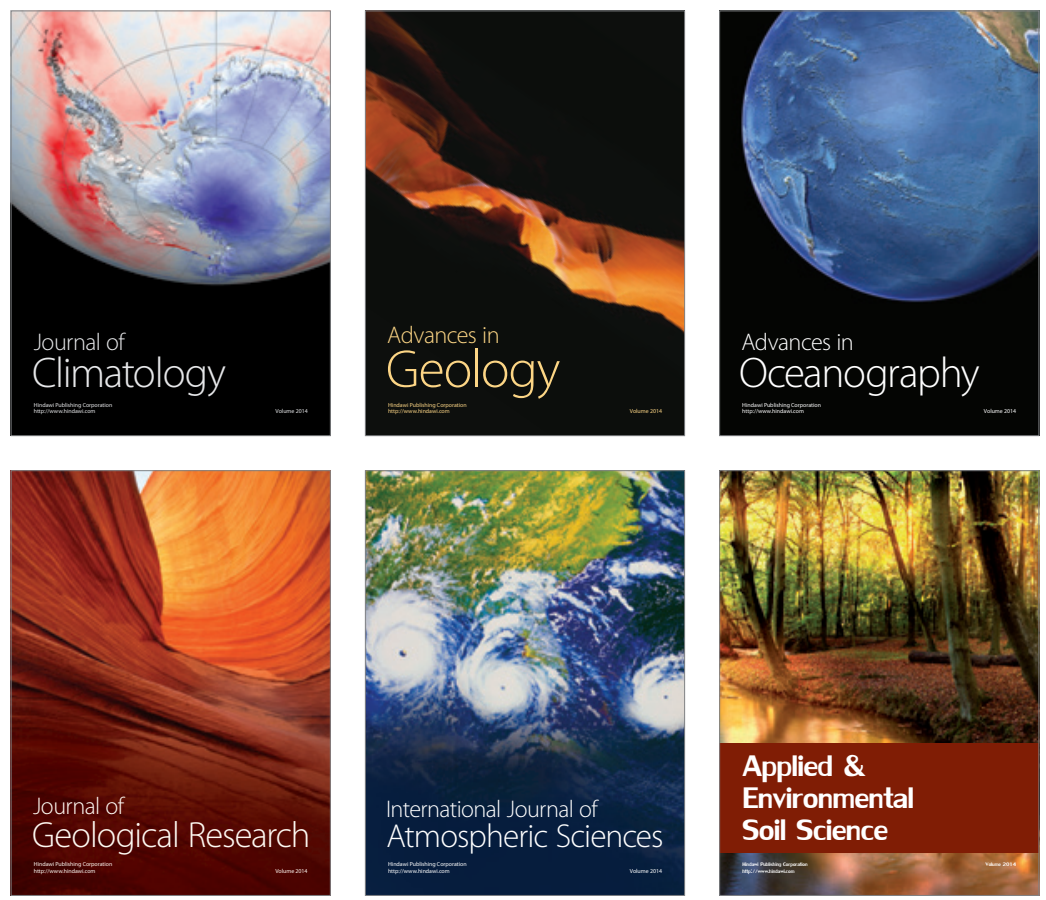
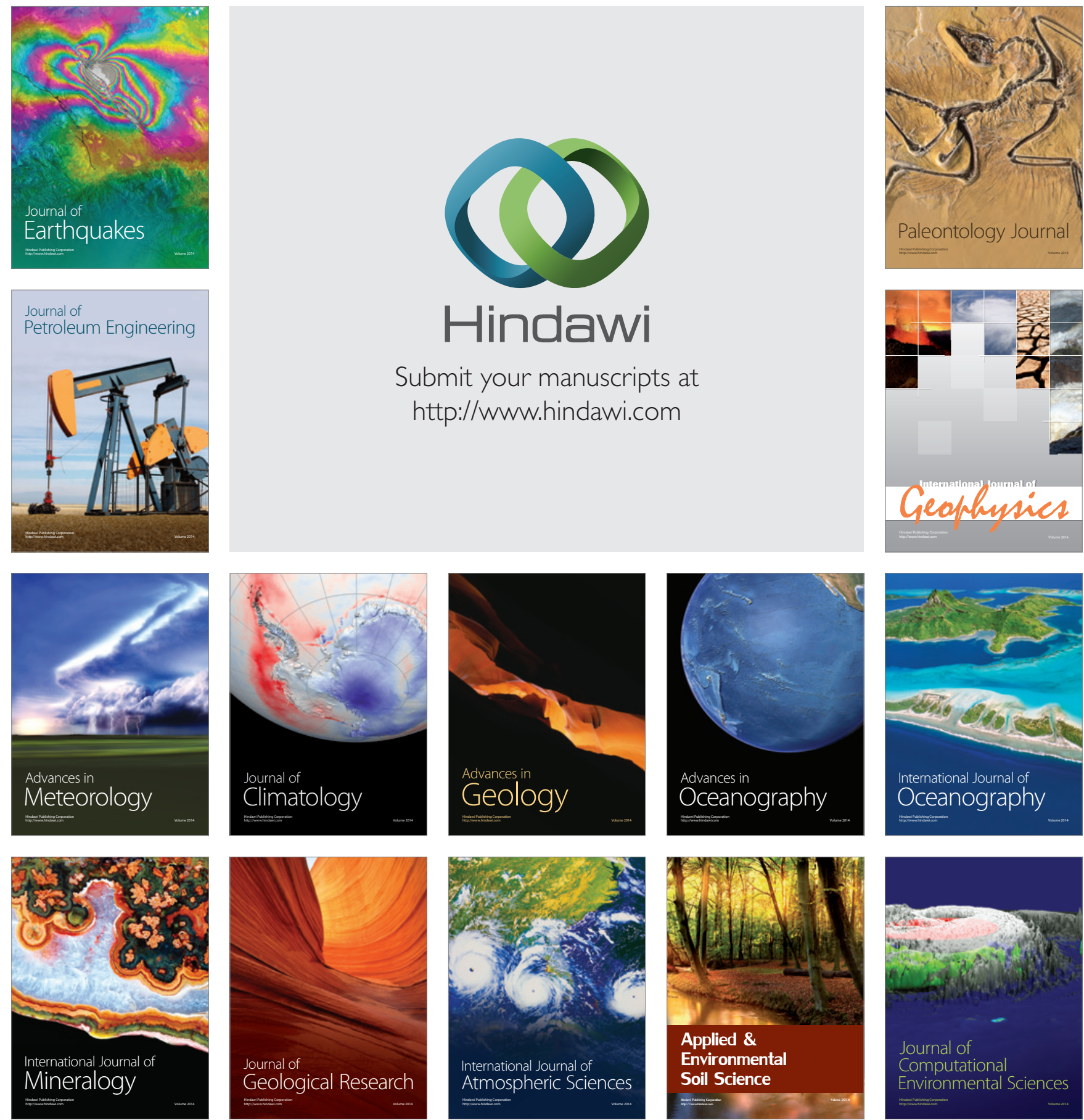